\title{
Determination of the wear performance of diamond saw blades using inductively coupled plasma
}

\author{
SERKAN INAL ${ }^{1}$, ILKER ERKAN $^{2, *}$ (D) and KERIM AYDINER ${ }^{1}$ \\ ${ }^{1}$ Department of Mining Engineering, Karadeniz Technical University, Trabzon, Turkey \\ ${ }^{2}$ Department of Mining Engineering, Gumushane University, Gumushane, Turkey \\ e-mail: serkan.inal@ktu.edu.tr; ilkererkan@gumushane.edu.tr; aydiner@ktu.edu.tr
}

MS received 23 November 2017; revised 4 January 2019; accepted 30 January 2019; published online 29 April 2019

\begin{abstract}
Saw blades are one of the most used cutting tools. They compose the expensive parts of a cutting machine. Therefore, saw-blade wear is an important parameter governing the economy of the cutting process. Significant savings could be made when it is controlled effectively. In this study, a new methodology is employed for the determination of the saw-blade wear in the cutting of two types of marble. Wear of segments is determined by high-precision inductively coupled plasma method. Two types of marbles were used to investigate the wear performance of diamond-impregnated segments of circular saw-blade matrix. Taguchi mixed design L16 $\left(4^{3} 2^{1}\right)$ is used as an experimental design and the results are evaluated statistically with Minitab. The results reveal that the specific wear rate (SWR) of Beige marble increases with the increase of the peripheral speed, traverse speed, depth of cut and down-cut mode operation. Additionally, it is demonstrated that the traverse speed and peripheral speed are the dominant cutting parameters affecting the SWR. It is also seen that similar trends are observed for Onyx marble (excluding peripheral speed). Finally, it is concluded that the proposed models can be effectively used for the estimation of the SWR.
\end{abstract}

Keywords. Diamond; saw blade; wear; marble; Taguchi.

\section{Introduction}

The use of the natural stones as a construction and decoration material has increased recently due to the increasing demand and technological advancements in the sector. World stone production grew 8 times in 40 years, which is higher than that of the economic system considered as a whole. In 2015 , gross yearly production of the natural stone industry was 286 million tonnes; 140 million tonnes raw material was produced from this output. About 83 million tonnes of this was supplied to market as the processed final product [1]. Diamond saw-blade cutting is one of the most commonly used methods for the machining and processing of natural stones. Higher material removal rate could be obtained by this method when compared with the other conventional machining techniques. The technology provides fast, economic and flexible cutting abilities. Energy consumption and cutting tool wear are two main factors affecting the cost of cutting operations. Therefore, these factors should be effectively managed in order to reduce the operation costs. For this purpose, many studies have been conducted on the cutting performances of circular sawing machines, diamond segmented frame machines and diamond wire cutting machines. In the related works, the

*For correspondence cutting forces and energy consumption of the machine were analysed [2-9]. Additionally, the effects of the cutting parameters $[2-4,7,9,10]$ and rock properties $[3,5,10-16]$ on the cutting performance of the diamond saw blades were investigated in detail.

Wear of saw blades is an important parameter affecting the economy of the cutting process, which can provide a significant saving when controlled effectively. The wear can be defined as a mass loss of diamond tool while interacting with the rock $[4,17-21]$. The wear mechanism of a segment is governed by the mechanical interaction between the rocks and cutting tools. Tönshoff et al [19] defined the mechanical interaction between the tool and workpiece in the diamond saw-blade cutting of stones. As depicted in figure 1, these mechanical interactions include the workpiece deformation (elastic and plastic) by the cutting edges, friction between the stone and diamonds and/ or matrix, and friction between the swarf and matrix (see figure 1). These interactions cause wear in the diamond grain and matrix during the cutting operation [7, 19]. It can be noted that the wear of diamonds and matrix should be balanced to reduce segment wear and maintain constant efficiency in the cutting operation [7, 19, 22-24].

Various attempts have been made to investigate wear in the saw blades. Luo and Liao [23] analysed the wear characteristics of diamond grits impregnated to segments 


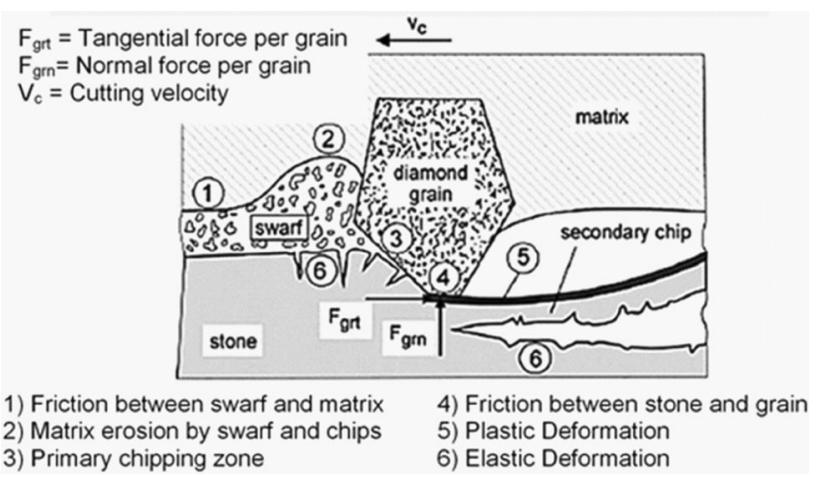

Figure 1. Mechanical interaction between the tool and workpiece in stone cutting Tönshoff et al [19].

with different mesh sizes using scanning electron microscope (SEM) analysis. The authors classified the diamonds as polished, micro/macro-fractured, pulled-out and even whole diamond without any significant surface damages. In the study, it was also revealed that the specific wear rate (SWR) increased with the increase of the cone indenter hardness. Additionally, it was concluded that the SWR increased with the increased in shore hardness and rock brittleness following a decrease [23]. Buyuksagis [26] investigated the cutting mode effect on the SWR. The results of the study demonstrated that the up-cutting mode was more efficient than the down-cutting mode. Yilmaz [27] determined a good correlation among the SWR, mineral content and hardness (Vickers and Rosiwal). Y1lmaz et al [28] determined the relationships between the mineralogical properties of granites and SWR. In the study, it was found that the SWR was correlated with the maximum particle size of feldspar and quartz. It was also revealed that a good relation existed between the SWR and the SWR index. Additionally, it was seen that the SWR index was related to Rosiwal hardness of these minerals and the maximum particle size of the feldspar. Bayram [17] examined the relationships between the saw-blade wear and some rock properties. The researcher found that the sawblade wear decreased with the increase of Böhme surface abrasion. In another study, Yllmaz [14] compared sandwich-core saw blade and a conventional saw blade based on the process efficiency. The results indicated that the new type of saw blade presented higher cutting performance in terms of the noise level, energy consumption, segment wear and stability figures. Aydin et al [13] investigated the effect of some rock properties and the cutting parameters on SWR. They reported an increase in SWR as a result of peripheral and traverse speed increases. The authors also claim that coolant fluid flow rate and cutting depth have negative effect on SWR. Among the physico-mechanical properties, micro-hardness is an important parameter having effect on SWR. Their work also revealed that SWR is mainly affected by the mineralogical properties of rocks instead of the physico-mechanical properties (except microhardness).

In the measurement of the saw blade wear, some methods such as laser measurements and mass loss determination were commonly employed [13, 29, 30]. There are some advantages of the new method proposed in this study against the other methods. With the mass loss determination method, the cutting tool wear is small for each experiment. Therefore more experiments must be conducted to effectively determine the wear of cutting tool [29]. On the other hand, in case of the laser method the cutting tool has to be firstly removed from the device and cleaned. Then the cutting tool wear is measured by the laser method based on the suggestions recommended by Yilmaz [14]. This technique can be also considered as ineffective due to the time required for measurements. Additionally, in case of the laser method, it could be very hard to obtain accurate results representing the wear of whole cutting surface due to different wear rates that can be observed in the other segment parts unscanned by the laser.

Different from the earlier studies documented, this study proposes a new methodology for the determination of SWR. In the new methodology, the SWR is derived from the chemical analysis results of the swarfs and chips, included in the coolant fluid.

Despite the mass loss and laser techniques, this new approach enables determining the wear of segments with collecting particles during the cutting process. Therefore, this approach prevents time losses and reduces the operation cost by supplying continuous cutting conditions. The new method is also thought to reduce the measurement error since it allows increasing the data representing the whole saw-blade segment surfaces. It can be noted that the particles (swarfs and chips) must be carefully collected in a tank without scattering around. Therefore this method requires higher precautions to prevent this situation. In this study, barricades were employed around the machine in order to direct the particles into the tank.

In this study, the effects of the cutting parameters (the peripheral speed, traverse speed, depth of cut and cutting mode) on the sawing performance of saw blade are also investigated for two types of marbles. Additionally, some statistical models were developed for the estimation of SWR.

\section{Materials and methods}

In this study, the sawing experiments were conducted on two marbles (Beige and Onyx) from Erzincan and Bayburt province (from the North-east part of Turkey). Some properties of the marbles are presented in table 1. The chemical compositions of the marbles are also provided in table 2. Samples with the dimensions $30 \times 10 \times 15 \mathrm{~cm}^{3}$ (length $\times$ width $\times$ thickness) were used in the 
Table 1. Some properties of the marbles.

\begin{tabular}{lcc}
\hline Rock properties & Beige & Onyx \\
\hline Mohs hardness & $4-4.5$ & 3 \\
Specific weight $\left(\mathrm{g} / \mathrm{cm}^{3}\right)$ & 2.70 & 2.72 \\
Porosity $(\%)$ & 0.195 & 0.13 \\
Average abrasion value $\left(\mathrm{cm}^{3} / 50 \mathrm{~cm}^{2}\right)$ & 25.93 & 11.26 \\
Water adsorption $(\%)$ & 0.15 & 0.05 \\
Pressure resistance $(\mathrm{MPa})$ & 68.72 & 73.14 \\
\hline
\end{tabular}

experiments. These samples were pre-cut in these dimensions from the blocks and then delivered to the laboratory. The cutting procedure of the samples was conducted with high care and precision in order to prevent damages on the marble. The samples are tightened up carefully before the experiments to avoid movements of the samples during the cutting.

An adequate distance (approximately $2 \mathrm{~cm}$ ) was provided between two cutting lines to avoid the development of micro-fractures, which could affect the next cutting lines.

A computer-controlled experimental sawing machine is employed in the tests (see figure 2). The machine consists of a cutting unit, instrumentation and a personal computer. The diameter of the saw blade used in the experiments is $40 \mathrm{~cm}$; 28 diamond-impregnated segments were mounted on the blade. Two $0.75 \mathrm{~kW}$ AC motors provide movements (forward-backward and up-down) of the saw blade on horizontal plane. Rotation of the saw blade is provided by a $4 \mathrm{~kW}$ AC motor. The motion of the wagon on the cutting line is controlled by a $0.75 \mathrm{~kW}$ AC motor. The machine is equipped with industrial and electronic cards to control the cutting variables such as traverse speed, cutting depth, cooling fluid flow and peripheral speed.

In the study, a new methodology for the determination of the SWR was employed. This method is based on the analysis of the particles removed from the rocks and sawblade matrix using the inductively coupled plasma (ICP) method. The particles from the worn matrix surfaces and ground parts of the rock were removed with the coolant fluid and the mixture was collected in a container for each test. The particles were then precipitated for further analyses. Solid-liquid separation procedure was conducted for the precipitated materials. The solid particles were then dried in hot air for the preparation of materials for further

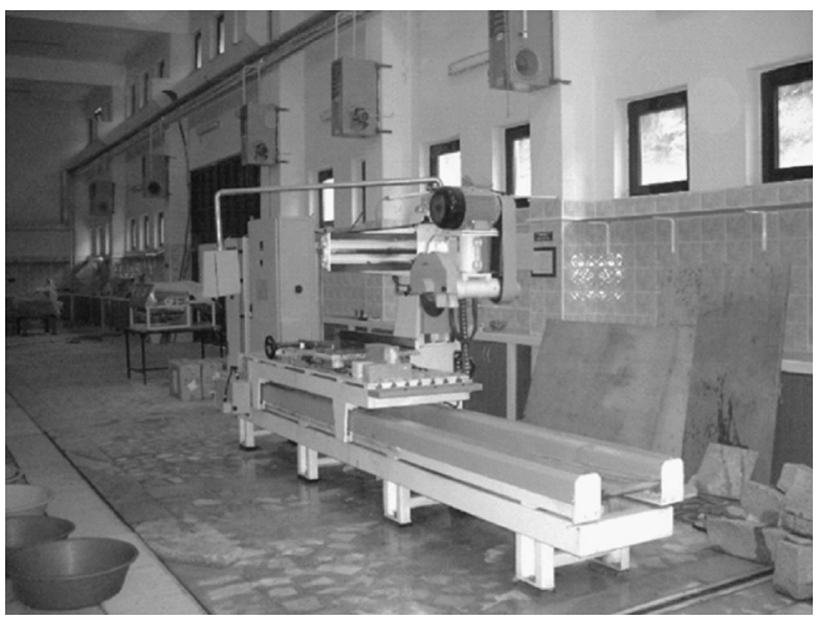

Figure 2. Experimental set-up.

chemical analyses using the ICP method. The ICP analyses of all samples were conducted at ACME laboratories in Canada using an ICP-MS analyser.

The chemical results demonstrated that high correlations (0.7-0.95) existed between the main components of the saw-blade matrix $(46 \% \mathrm{Cu}, 29 \% \mathrm{Fe}$ and $25 \% \mathrm{Co})$. This indicates that worn parts of the matrix were well collected from the fluid tank (accommodated on the bottom) of the cutting machine. Copper, one of the main components of the saw blade, has the highest contribution in the matrix, with higher quantities of copper detected than the other components by the ICP analyses. Therefore, it was used as the primary component to follow the wear of the saw blade to reduce errors of chemical analyses due to analysis precisions. Finally, the copper amount of the saw blade removed during each cutting test was calculated via Eq. (1) based on the mass balance phenomenon:

$$
C_{t} x M_{t}=C_{m} x W_{m}+C_{r} x M_{r}
$$

where $C_{\mathrm{t}}$ is total $\mathrm{Cu}(\%), M_{\mathrm{t}}$ is total amount of chips $(\mathrm{g}), C_{\mathrm{m}}$ is $\mathrm{Cu}(\%)$ of matrix, $W_{\mathrm{m}}$ is wear of the saw-blade matrix $(\mathrm{g}), C_{\mathrm{r}}$ is $\mathrm{Cu}(\%)$ of rock and $M_{\mathrm{r}}$ is amount of cut rock (g) (calculated).

On the other hand, the SWR, which is commonly used in the literature, is employed to assess the performance of saw-blade wear. The parameter expresses the ratio of the radial wear to sawed area of material (Eq. (2)):

Table 2. Chemical compositions of the marbles.

\begin{tabular}{lcccccc}
\hline Marble type & $\mathrm{Cu}(\mathrm{ppm})$ & $\mathrm{Fe}(\%)$ & $\mathrm{Sr}(\%)$ & $\mathrm{Ca}(\%)$ & $\mathrm{Mg}(\%)$ & $\mathrm{S}(\%)$ \\
\hline Onyx & 8 & 0.81 & 58 & 36.65 & 0.09 & 0.23 \\
Beige & 14 & 0.04 & 142 & 36.47 & 0.31 & 0.17 \\
\hline
\end{tabular}




$$
\mathrm{SWR}=\frac{W m}{L d}
$$

where SWR is specific wear rate $\left(\mathrm{mg} / \mathrm{m}^{2}\right), W_{\mathrm{m}}$ is wear of the saw-blade matrix $(\mathrm{mg}), d$ is depth of cut $(\mathrm{m})$ and $L$ is cutting distance $(\mathrm{m})$.

The sawing experiments were performed for the investigation of the SWR based on the cutting parameters. The cutting parameters were studied in variable levels as seen in table 3. During the cutting tests, the flow rate of coolant fluid was kept constant. Taguchi experimental design and analysis method is employed for the experiments. The method allows evaluating the effect of parameters on the response of an experimental study with a limited run of experiments [31]. Taguchi mixed design L16 $\left(4^{3} 2^{1}\right)$ was used to reduce the number of the experiments and to discover the synergic effect among all the operational parameters (see table 4).

Main effects and ANOVA analyses were also performed using Minitab (2017) according to $S / N$ ratios, which define the ratio of signal to noise. The signal is the value given by the system and the expected value of measurements. Noise factors are the undesirable factors in the measured values due to which performance characteristics of variables derivate from target values. Therefore, the effects of the noises to the system should be minimized. For this purpose, three methods: (i) smaller is the best, (ii) nominal is the best and (iii) bigger is the best are used widely [32]. In this study, smaller is the best approach was used to find out $S /$ $N$ values.

\section{Results and discussion}

The extent of $\mathrm{Cu}$ removal amounts from the matrix and the calculated SWR values of each experiment are presented in table 5. $S / N$ ratios of the SWR for the cutting parameters at each level were calculated statistically with Taguchi analysis (see table 6). Delta values were calculated by subtracting maximum and minimum values to compare the relative magnitude of the parameters. According to these values, ranks of parameters were determined (see table 6). The traverse speed was determined as the most significant factor for Beige marble, followed by the peripheral speed, depth of cut and cutting mode. On the other hand, the peripheral speed was ranked first as an important parameter for Onyx marble, followed by the traverse speed, depth of cut and cutting mode.

Analyses of variance (ANOVA) were also performed for the determination of the contribution rates of the cutting parameters on SWR (see table 7). As is well known, $P$ values have been used to test the significance level of the cutting parameters. It is the probability that the test statistics will take on a value that is at least as excessive as the observed value of the statistic when the null hypothesis $\left(\mathrm{H}_{0}\right)$ is true. To classify a parameter as significant, $P$ value should be lower than the alpha $(\alpha)$ value determined by the significance test [33]. Considering the $P$ values, all cutting parameters were found to be statistically significant at $95 \%$ $(\alpha=0.05)$ for Beige marble, excluding the cutting mode, whose $\alpha$ is slightly higher (0.053). Additionally, only the peripheral speed was statistically significant at this level for Onyx marble. Also, significances of parameters were controlled via $F$ tabulated values and $F$ calculated values comparison. Some parameters acquire bigger $F$ calculated values than $F$ tabulated values. Only $F$ value of cutting mode for Beige marble is slightly lower than tabulated $F$ value, as expected (see table 7). For Beige marble, the contribution rates were determined as $47.41 \%, 29.09 \%$, $14.99 \%$ and $4.76 \%$ for the traverse speed, peripheral speed, depth of cut and cutting mode, respectively. The contribution rates of the parameter for Onyx marble are $52.00 \%$ $(\alpha=0.05)$ for the peripheral speed and $29.41 \%$ for the traverse speed $(\alpha=0.12)$.

The effects of the cutting parameters on the SWR are depicted in figure 3, using the mean values of $S / N$ ratios from table 6. The figures demonstrate that, for Beige marble, the increase in SWR is resulted by the traverse speed and peripheral speed increases. Additionally, the depth of cut and applying down-cut mode operation method contributed to the increase in SWR. Similar trends (excluding the peripheral speed) were also observed for Onyx marble. Different results were obtained for the effect of the peripheral speed on the SWR for cutting of two marbles. As defined by Liao and Luo [34], the low cyclic fatigue, which can cause fracturing diamond particles and matrix, can be attributed to flush erosion. Aydin et al [13] revealed that SWR increased dramatically over a critical speed. The results of this study showed that minimal peripheral speed is $38 \mathrm{~m} / \mathrm{s}$ for Onyx, which is relatively hard to cut compared with Beige marble. Therefore, with this value higher wear rates were observed due to low cyclic fatigue. Above this

Table 3. Factors and their levels adopted for the experimental design.

\begin{tabular}{lcccc}
\hline Parameters & Level 1 & Level 2 & Level 3 & Level 4 \\
\hline Peripheral speed $(\mathrm{m} / \mathrm{min})$ & 34 & 38 & 42 & 46 \\
Traverse speed $(\mathrm{m} / \mathrm{min})$ & 0.75 & 1.125 & 1.5 & 1.875 \\
Depth of cut $(\mathrm{cm})$ & 1.5 & 2 & 2.5 & 3 \\
Cutting mode & Down-cut & Up-cut & - & - \\
\hline
\end{tabular}




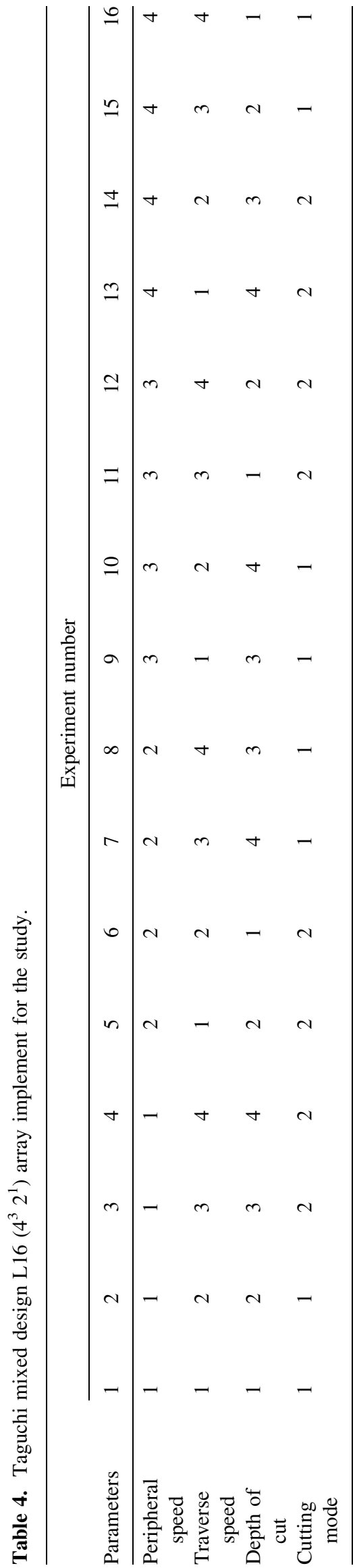

value, SWR decreases with an increase of the peripheral speed for Onyx marble. Ertingshausen [35] defined the equivalent chip thickness to clearance as slurry thickness ratio, which may markedly affect the wear rate of the matrix. This result shows that secondary wear of matrix caused by chips may be more effective in the cutting of Onyx marble. Aslantas et al [4] stated that the chips were removed faster with increasing peripheral speed. This helps reduce the SWR. Contrarily, SWR value increased dramatically depending on the peripheral speed increase above $38 \mathrm{~m} / \mathrm{s}$ for Beige marble. This value indicates the critical peripheral speed for the cutting of Beige marble. Tumac [12] reveal that the matrix and diamonds are burnt or broken when the peripheral speed is selected over the critical value. Also, Ersoy and Atıc1 [6] claim that continued increase of peripheral speed over critical value causes polished segment of the blade and pull-out. It can be stated that over the critical peripheral speed, the temperature can dramatically increase and this causes higher SWR. It can be also noted that different wear kinematics may cause different results in terms of the SWR for two marbles. Therefore, it can be stated that the optimum peripheral speeds must be determined based on the factors affecting the wear of the cutting tool. It was determined that SWR increased as a result of the increase in the depth of cut for Beige marble. For Onyx marble, SWR presented a slightly decrease after $2.5 \mathrm{~cm}$. In the relevant literature, contradictory results on the effect of the cutting depth also exist. Karakus [36] concluded that the cutting depth has a positive effect on SWR. Contrary to his findings, Aydin et al [13] pointed out that lower SWR values can be obtained when higher cutting depths are selected. The possible reason for obtaining different results is mainly originated from the limits of the cutting parameters. The results indicated that the up-cut mode was better than the down-cut mode, just in small quantities in terms of SWR. This finding was supported by the study conducted by Buyuksagis [26]. The differences in the kinetics of cutting modes are the main reason for obtaining different results for these two cutting modes. In the down-cut mode, the cutting begins with a maximum chip thickness. Therefore, high impact loads increase the wear acting on the diamond grits and matrix as well. Additionally, Konstanty [37] and Tönshoff et al [19] pointed out that the cutting mechanism affects the diamonds as all segments are exposed to wear at equitably the same rates in up-cutting mode while the wear rate of individual segments varies in down-cutting mode. In the current study, a linear relationship has been determined between SWR value and traverse speed. SWR showed a similar trend for two marbles based on the traverse speed. The finding is compatible with the studies documented in the relevant literature $[13,21]$. The tearing and fracturing of the diamonds due to high impact loads, insufficient penetration into rock and high lateral deviation of the saw at high traverse speeds are the main reasons for the observed 
Table 5. $\mathrm{Cu}$ removal amounts from the matrix and the SWR values for the experiments.

\begin{tabular}{|c|c|c|c|c|}
\hline \multirow[b]{2}{*}{ Exp. No } & \multicolumn{2}{|c|}{ Beige } & \multicolumn{2}{|c|}{ Onyx } \\
\hline & Wear of matrix (mg) & $\operatorname{SWR}\left(\mathrm{mg} / \mathrm{m}^{2}\right)$ & Wear of matrix (mg) & $\operatorname{SWR}\left(\mathrm{mg} / \mathrm{m}^{2}\right)$ \\
\hline 1 & 0.33 & 73.3 & 1.42 & 316.4 \\
\hline 2 & 1.05 & 176.3 & 2.30 & 383.4 \\
\hline 3 & 2.10 & 279.6 & 4.0 & 534.5 \\
\hline 4 & 3.58 & 388 & 7.39 & 821.4 \\
\hline 5 & 0.44 & 73.3 & 2.90 & 484.0 \\
\hline 6 & 0.33 & 73.3 & 1.65 & 366.6 \\
\hline 7 & 5.86 & 651.1 & 4.81 & 534.5 \\
\hline 8 & 5.90 & 785.7 & 4.77 & 635.5 \\
\hline 9 & 2.21 & 294.3 & 2.62 & 349.9 \\
\hline 10 & 5.60 & 621.1 & 2.39 & 266.3 \\
\hline 11 & 2.60 & 576.4 & 1.50 & 333.2 \\
\hline 12 & 3.55 & 591.3 & 2.10 & 349.9 \\
\hline 13 & 2.52 & 279.6 & 1.20 & 133.0 \\
\hline 14 & 4.21 & 561.5 & 1.75 & 232.9 \\
\hline 15 & 3.90 & 651.0 & 2.0 & 333.2 \\
\hline 16 & 3.27 & 725.8 & 1.5 & 333.2 \\
\hline
\end{tabular}

Table 6. S/N values of the SWR for the parameters at each level and delta statistics for the parameters.

\begin{tabular}{|c|c|c|c|c|c|c|c|}
\hline \multirow[b]{2}{*}{ Rock type } & \multirow[b]{2}{*}{ Parameters } & \multicolumn{4}{|c|}{$\operatorname{SWR}\left(\mathrm{mg} / \mathrm{m}^{2}\right)$} & \multirow[b]{2}{*}{ Delta (Max.-Min.) } & \multirow[b]{2}{*}{ Rank } \\
\hline & & Level 1 & Level 2 & Level 3 & Level 4 & & \\
\hline \multirow[t]{4}{*}{ Beige } & Peripheral speed & -45.79 & -47.20 & -53.97 & -54.35 & 8.56 & 2 \\
\hline & Traverse speed & -43.23 & -48.27 & -54.27 & -55.64 & 12.41 & 1 \\
\hline & Depth of cut & -46.76 & -48.49 & -52.80 & -53.27 & 6.51 & 3 \\
\hline & Cutting mode & -51.89 & -48.76 & - & - & 3.13 & 4 \\
\hline \multirow[t]{4}{*}{ Onyx } & Peripheral speed & -53.63 & -53.90 & -50.18 & -57.68 & 6.22 & 1 \\
\hline & Traverse speed & -49.26 & -49.70 & -52.51 & -53.92 & 4.66 & 2 \\
\hline & Depth of cut & -50.55 & -51.68 & -52.21 & -50.96 & 1.66 & 3 \\
\hline & Cutting mode & -51.57 & -51.12 & - & - & 0.45 & 4 \\
\hline
\end{tabular}

Table 7. Results of ANOVA (S/N) for the cutting parameters on the SWR.

\begin{tabular}{|c|c|c|c|c|c|c|c|c|}
\hline $\begin{array}{l}\text { Rock } \\
\text { type }\end{array}$ & $\begin{array}{l}\text { Source of } \\
\text { deviation }\end{array}$ & $\begin{array}{l}\text { Degree of } \\
\text { freedom }\end{array}$ & $\begin{array}{l}\text { Sum of } \\
\text { squares }\end{array}$ & $\begin{array}{c}\text { Mean } \\
\text { squares }\end{array}$ & $\begin{array}{c}\mathrm{F} \\
\text { value }\end{array}$ & $\begin{array}{c}\text { Tabulated F } \\
\text { value }\end{array}$ & $P$ value & $\begin{array}{c}\text { Contribution } \\
(\%)\end{array}$ \\
\hline \multirow[t]{6}{*}{ Beige } & A & 3 & 239.44 & 79.813 & 12.93 & 5.41 & 0.009 & 29.09 \\
\hline & B & 3 & 390.33 & 130.110 & 21.08 & & 0.003 & 47.41 \\
\hline & $\mathrm{C}$ & 3 & 123.43 & 41.142 & 6.67 & & 0.034 & 14.99 \\
\hline & $\mathrm{D}$ & 1 & 39.15 & 39.152 & 6.34 & 6.60 & 0.053 & 4.76 \\
\hline & $\mathrm{H}$ & 5 & 30.86 & 6.171 & & & & 3.75 \\
\hline & $\mathrm{T}$ & 15 & 823.21 & & & & & 100 \\
\hline \multirow[t]{6}{*}{ Onyx } & A & 3 & 106.204 & 35.401 & 5.79 & 5.41 & 0.044 & 52.00 \\
\hline & B & 3 & 60.071 & 20.024 & 3.28 & & 0.117 & 29.41 \\
\hline & $\mathrm{C}$ & 3 & 6.570 & 2.190 & 0.36 & & 0.786 & 3.22 \\
\hline & $\mathrm{D}$ & 1 & 0.815 & 0.816 & 0.13 & 6.60 & 0.730 & 0.40 \\
\hline & $\mathrm{H}$ & 5 & 30.564 & 6.113 & & & & 14.97 \\
\hline & $\mathrm{T}$ & 15 & 204.224 & & & & & 100 \\
\hline
\end{tabular}

A: Peripheral Speed (m/min), B: Traverse Speed (m/min), C: Depth of Cut (cm), D: Cutting Mode (down/up), H: Residual Error, T: Total 

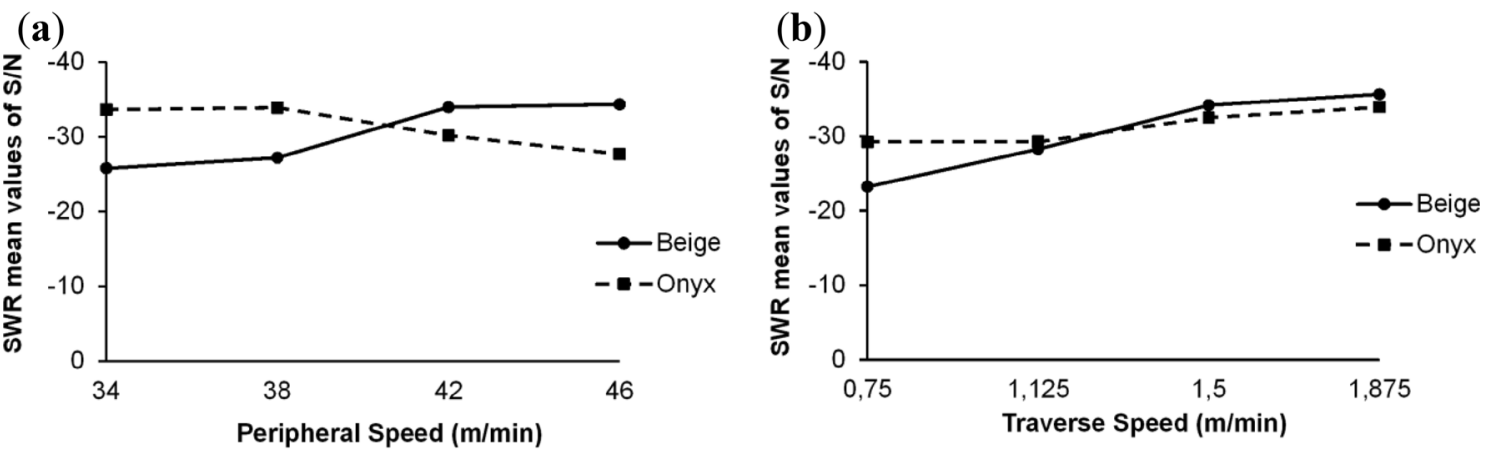

(c)
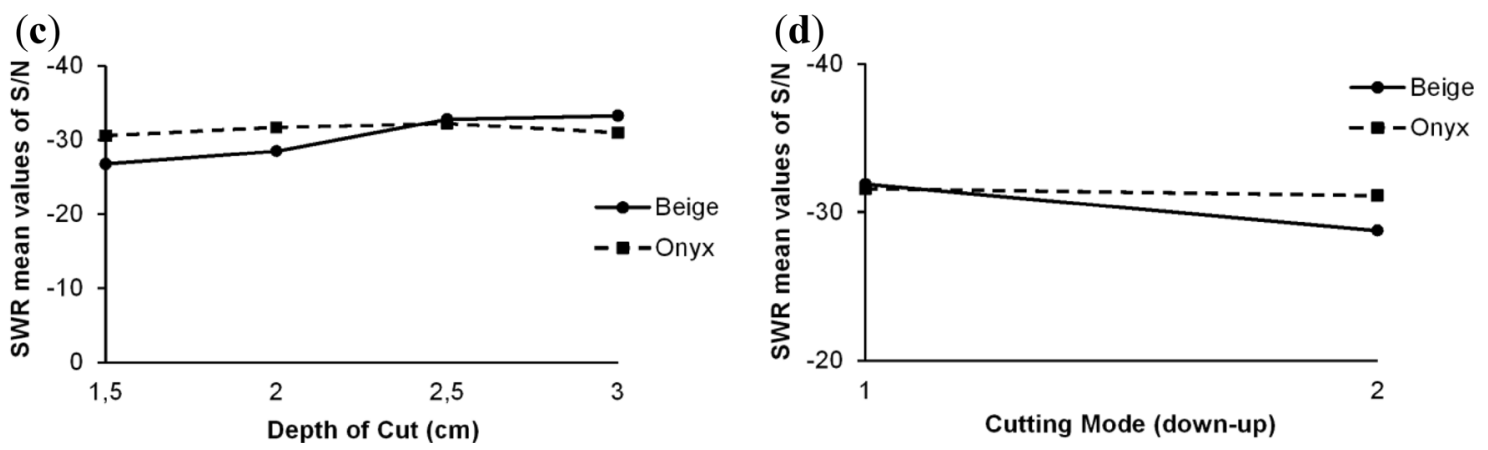

Figure 3. The effects of the cutting parameters on SWR: (a) peripheral speed, (b) traverse speed, (c) depth of cut and (d) cutting mode variable.

trend. By all these accounts, a detailed mechanism can be described.

As is well known, the mechanism of matrix and diamond wear is related to many factors. The operational parameters, matrix and diamond properties, rock properties and different kinds of mechanisms affect the cutting efficiency in terms of specific energy, cutting forces, specific removal rate and wear of cutting tool as well (see figure 1). Therefore, it is certainly necessary to specify which mechanism has a higher effect on the wear performance of diamonds and matrix. Researchers have a common idea that diamonds and matrix should wear in balance to sustain the cutting process with a maximum benefit of diamond grains $[7,8,19,22-25]$. If this necessity cannot be provided during the cutting process, diamond grains can be pulled out without use completely as a result of too fast matrix wear or the cutting edges and the matrix can become closer and segment loses its ability of cutting due to insufficient sweeping of swarfs when matrix wear is slower than that of the diamonds [19]. At this point, the protrusion of a diamond grain is very important and depends on these imbalanced wear conditions. Therefore, aiming at maximum protrusion of grains could reduce the total wear of the cutting tool (diamond and matrix together), which is highly dependent on matrix hardness [24]. The successive and continuous stages of cutting such as chip generation, erosion of matrix by chips and diamond sharpening by stone and chips should be properly controlled by the operational parameters to obtain well-balanced cutting conditions. At this point, the maximum chip thickness becomes very significant, which enhances the matrix wear as the precursor indicates due to possible step-up of the slurry thickness in cutting area [37]. In the literature, some researchers report that this parameter is related to the process efficiency, cutting forces, specific material removal rate and SWR [7, 8, 19, 24, 29, 37, 38]. Tönshoff and Warnecke [38] developed a fundamental model of mean chip thickness (hm) quantification for diamond in 1982 Eq. (3):

$$
\mathrm{hm}=\sqrt{\left(\frac{V f}{V c}\right)\left(\frac{1}{C \lambda r}\right) \sqrt{\frac{d}{D^{\prime}}}}
$$

where $\mathrm{hm}$ is mean chip thickness produced by a single diamond grit, $V_{\mathrm{f}}$ is traverse speed, $V_{\mathrm{c}}$ is peripheral speed, $C$ is active diamond grits number per unit area, $\lambda$ is the ratio of segment-to-segment length to segment length, $r$ is chip shape factor (ratio of mean chip width to mean chip thickness), $d$ is depth of cut and $D^{\prime}$ is diameter of saw blade.

This equation demonstrates that some of the operational parameters such as traverse speed, peripheral speed and the depth of cut affect the mean chip thickness very clearly. Also, Yllmaz [8] states that mean chip sizes are doubled when depth of cut and traverse speed are doubled. As a result, the produced chips get coarser and force ratio values (tangential force to normal force) decrease [8].

In this study, each marble produced different wear rates related to the operational parameters. This situation can be thought to be associated to the relative effectiveness of the mechanisms illustrated in figure 1 . The relative effects of these mechanisms could change depending on the rock 
Table 8. Statistical results of the multiple linear regression analysis concerning the cutting parameters.

\begin{tabular}{|c|c|c|c|c|c|c|c|c|c|c|c|}
\hline $\begin{array}{l}\text { Rock } \\
\text { type }\end{array}$ & Model & Term & Coefficient & SE & $\begin{array}{c}\text { SE of } \\
\text { estimate }\end{array}$ & $\begin{array}{c}\mathrm{T}- \\
\text { value }\end{array}$ & $\begin{array}{c}\text { Tabulated } \\
\text { T-value }\end{array}$ & $\begin{array}{c}\text { F-value of } \\
\text { model }\end{array}$ & $\begin{array}{c}\text { Tabulated } \\
\text { F-value }\end{array}$ & $\begin{array}{c}P \text { - } \\
\text { value }\end{array}$ & $\begin{array}{l}\text { Determination } \\
\text { coefficient }\left(\mathrm{R}^{2}\right)\end{array}$ \\
\hline \multirow[t]{12}{*}{ Beige } & \multirow[t]{5}{*}{ Eq. (4) } & $\mathrm{S}$ & -1200 & 251 & \multirow[t]{5}{*}{93.312} & -4.78 & \multirow[t]{5}{*}{2.20} & \multirow[t]{5}{*}{23.76} & \multirow[t]{5}{*}{3.36} & 0.001 & \multirow[t]{5}{*}{89.63} \\
\hline & & A & 27.32 & 5.22 & & 5.24 & & & & 0.000 & \\
\hline & & B & 404.4 & 55.6 & & 7.27 & & & & 0.000 & \\
\hline & & $\mathrm{C}$ & 96.6 & 41.7 & & 2.31 & & & & 0.041 & \\
\hline & & D & -143.2 & 46.7 & & -3.07 & & & & 0.011 & \\
\hline & \multirow[t]{4}{*}{ Eq. (5) } & $\mathrm{S}$ & -1226 & 218 & \multirow[t]{4}{*}{62.377} & -5.63 & \multirow[t]{4}{*}{2.18} & \multirow[t]{4}{*}{43.38} & \multirow[t]{4}{*}{6.59} & 0.005 & \multirow[t]{4}{*}{97.02} \\
\hline & & A & 19.13 & 5.38 & & 3.56 & & & & 0.024 & \\
\hline & & B & 443.1 & 57.4 & & 7.72 & & & & 0.002 & \\
\hline & & $\mathrm{C}$ & 167.2 & 39.5 & & 4.24 & & & & 0.013 & \\
\hline & \multirow{3}{*}{ Eq. (6) } & $\mathrm{S}$ & -1622 & 365 & \multirow[t]{3}{*}{89.051} & -4.44 & \multirow[t]{3}{*}{2.16} & \multirow[t]{3}{*}{17.64} & \multirow[t]{3}{*}{5.78} & 0.007 & \multirow[t]{3}{*}{87.58} \\
\hline & & A & 35.17 & 7.68 & & 4.58 & & & & 0.006 & \\
\hline & & B & 434.1 & 81.9 & & 5.30 & & & & 0.003 & \\
\hline \multirow[t]{9}{*}{ Onyx } & \multirow[t]{3}{*}{ Eq. (7) } & $\mathrm{S}$ & 1081 & 232 & \multirow[t]{3}{*}{97.542} & 4.65 & \multirow[t]{3}{*}{2.16} & \multirow[t]{3}{*}{15.58} & \multirow[t]{3}{*}{3.81} & 0,000 & \multirow[t]{3}{*}{70.56} \\
\hline & & A & -23.70 & 5.45 & & -4.35 & & & & 0,001 & \\
\hline & & B & 203.7 & 58.2 & & 3.50 & & & & 0,004 & \\
\hline & \multirow[t]{4}{*}{ Eq. (8) } & $\mathrm{S}$ & 600 & 296 & \multirow[t]{4}{*}{84.947} & 2.02 & \multirow[t]{4}{*}{2.18} & \multirow[t]{4}{*}{3.74} & \multirow[t]{4}{*}{6.59} & 0.113 & \multirow[t]{4}{*}{73.70} \\
\hline & & A & -16.43 & 7.33 & & -2.24 & & & & 0.088 & \\
\hline & & B & 220.1 & 78.2 & & 2.82 & & & & 0.048 & \\
\hline & & $\mathrm{C}$ & 72.2 & 53.7 & & 1.35 & & & & 0.250 & \\
\hline & Eq. (9) & $\mathrm{S}$ & 1976 & 328 & 102.908 & 6.03 & 2.14 & 23.23 & 5.99 & 0,001 & 79.48 \\
\hline & & A & -39.22 & 8.14 & & -4.82 & & & & 0.003 & \\
\hline
\end{tabular}

S: Constant, A: Peripheral Speed (m/min), B: Traverse Speed (m/min), C: Depth of Cut (cm), D: Cutting Mode (down/up)

properties. As can be seen in table 7 , the effects of the peripheral speed, traverse speed, depth of cut and cutting mode variables on wear of Beige marble are at a significant level $(95 \%)$. Contrary to this, while cutting Onyx, which is two times abrasive than Beige marble, the peripheral speed and traverse speed become more of an issue (see table 7). As mentioned before, the different types of mechanisms cause wear of segments, but it can be thought that the effectiveness of these mechanisms varies depending on the rock properties, especially abrasiveness of rock. Therefore, chips and saw-blade friction effect became dominant during the cutting process of Onyx. Also, with a decrease of the peripheral speed and increase of the traverse speed, coarser chips are produced and as a result of this the scratching possibility of the matrix by chips (while removing chips through coolant fluid) is enhanced. The same mechanism affects also the Beige marble, but the dominant segment wear mechanism is the friction between the rock and the grain. Additionally, the cutting mode effect cannot be observed in Onyx because the chips on segmental blades move within a slot and are sucked back into the cutting zone of the next segment [37]. Therefore, the cutting mode effect was observed only in cutting of less abrasive Beige marble. Contrary to this, the advantage of up-cutting mode may be low on wear rate due to the friction mechanism between grain and stone since wear caused by friction mechanism between chips and matrix friction is more effective in cutting Onyx due to its abrasiveness.
Multiple linear regression analysis method was used to establish a mathematical model for the estimation of the SWR (see table 8). Following models were developed for two marbles in three categories: as general (with cutting mode parameter), down-cut mode and up-cut mode. The models were found to be statistically valid at $95 \%$ confidence (Eqs. (4)-(8)).

$\mathrm{SWR}_{\text {Beige }}=-1200+27.32 A+404.4 B+96.6 C-143.2 D$

$\mathrm{SWR}_{\text {Down-cut-Beige }}=-1226+19.13 A+443.1 B+167.2 C$

$$
\begin{gathered}
\mathrm{SWR}_{\mathrm{Up}-\text { cut-Beige }}=-1622+35.17 A+434.1 B \\
\mathrm{SWR}_{\text {Onyx }}=1081-23.70 A+203.7 B \\
\mathrm{SWR}_{\text {Down-cut-Onyx }}=600-164.43 A+220.1 B+72.2 C
\end{gathered}
$$

$$
\mathrm{SWR}_{\mathrm{Up}-\text { cut-Onyx }}=1976-39.22 A
$$

where $A$ is peripheral speed, $B$ is traverse speed, $C$ is depth of cut and $D$ is cutting mode variable.

Verifications of the models were undertaken by considering the behaviour of $R^{2}, t$ test, $F$ test and (see table 8) residual analysis (see figure 4). The $R^{2}$ values for the models vary between 0.7056 and 0.9702 , indicating that the 

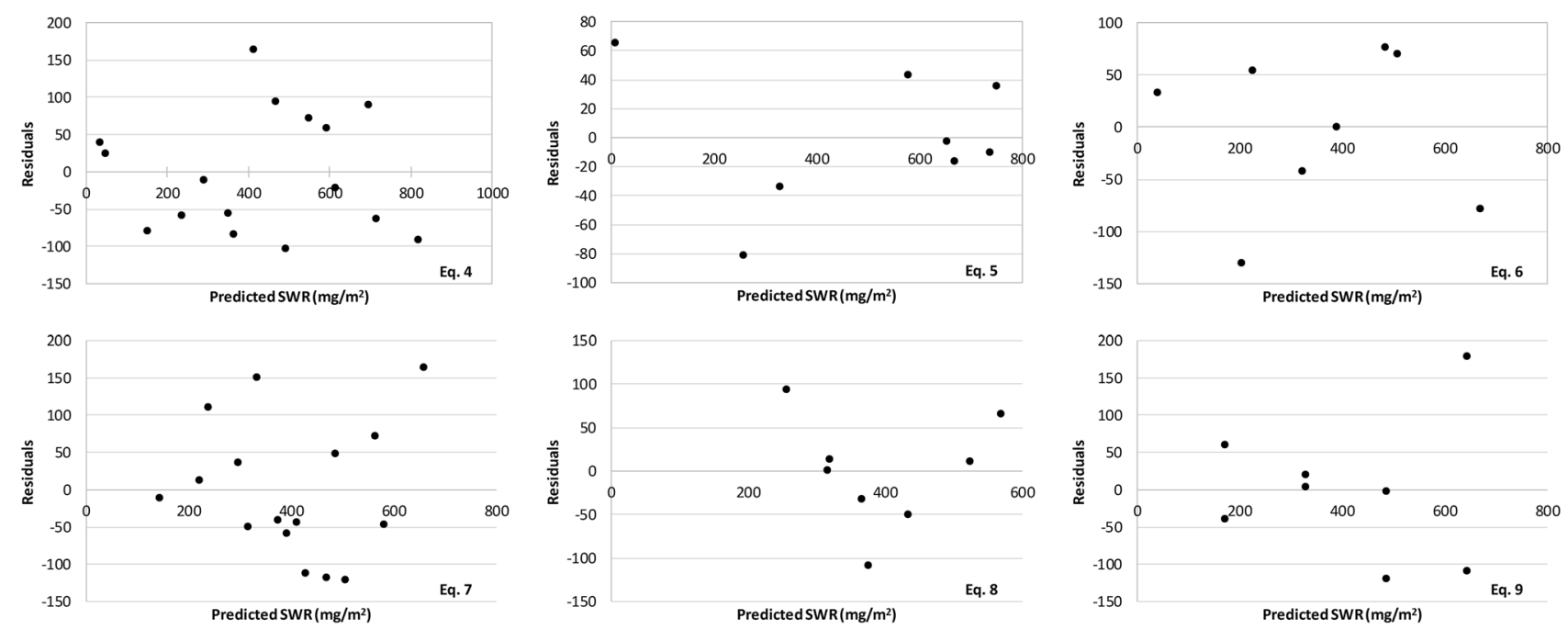

Figure 4. Residuals against the predicted specific wear rate.

relationships between predicted and observed SWRs are of high degree. Additionally, all models' significances were also checked by $F$ and $t$ tests at the $95 \%$ confidence level. Both calculated values for $t$ and $F$ values are greater than tabulated values, suggesting that the models (excluding Eq. (8)) built are statistically valid. Plots of the modelpredicted SWR against residuals also confirm the accuracy of the models (excluding Eq. (8)), since the residuals appear to be randomly scattered about the horizontal axis (see figure 4). On the other hand, $P$ values of parameters in Eq. (8) are found to be higher than 0.05 in each step of elimination method used in regression analysis (only the enter method is given in table 8). Also, the pattern of residuals scattered like $\mathrm{V}$ shape can be seen in figure 4, which indicates that Eq. (8) is not valid.

\section{Conclusions}

In this study, a new methodology for the measurement of segment wear was employed and the wear performance of a saw blade in the cutting of two types of marble was investigated. Core findings of the study are summarized as follows.

i. The study showed that the proposed method can be used with a high precision for determining saw-blade wear. It can be stated that the new method provides an opportunity to perform the measurement without stopping the cutting process.

ii. It was revealed that the SWR for Beige increased with the increase in the peripheral speed, traverse speed, depth of cut and down-cut mode operation. Additionally, the traverse speed and peripheral speed were determined as dominant operation variables affecting the SWR. Moreover, SWR decreased with the increase of the peripheral speed, differing from the effects of other cutting parameters on the SWR for Onyx marble.

iii. It was concluded that the effects and contribution rates of the parameters on SWR could vary, although similar rocks were cut (marbles). Therefore, it can be recommended that the cutting parameters must be chosen specifically for each rock.

iv. It can be noted that different types of mechanisms play roles for segment wear. The study showed that the chips and saw-blade friction effect were mainly observed in the cutting of Onyx due to its higher abrasiveness. This result indicates that the rock properties could also govern the effectiveness of the mechanisms affecting segment wear. Therefore, chip thickness should be considered as an important criterion for the selection of the cutting parameter.

v. It can be recommended that lower values of the traverse speed and peripheral speed (in the condition of being above minimal peripheral speed) could be chosen with higher cutting depths for obtaining best results in terms of SWR.

vi. It was found that the up-cutting mode presented slightly better performance over the down-cutting mode in terms of SWR

vii. The modelling results showed that the proposed models can be effectively used for the estimation of SWR based on the cutting parameters.

Following studies could be conducted on the study subject. These studies would make contributions to existing literature and the natural stone sectors.

i. In this study, experiments were carried out for two types of marbles. Other rock types such as granite 
could be also used as materials subjected to cuts. The cutting performances of the diamond saw blades could be investigated for different types of rocks based on the new methodology proposed. Thus, sawblade wear measurement could be carried out with a high accuracy and the sawing mechanism for the rocks can be clearly defined.

ii. In the study, SWR was modelled using multiple linear regression analysis. SWR could be also modelled with other forecasting methods such as artificial neural networks. The results of the different methods could be compared by the multiple linear regression analysis to see the performance of the proposed models.

iii. Research works by this method can be expected to reveal the effect of rock chips in the cutting region of different peripheral speeds. Further investigation of different abrasiveness values of rocks could be helpful to understand all phases of wear mechanism, especially in terms of producing ship sizes during cutting process.

\section{List of symbols}

\begin{tabular}{|c|c|}
\hline$C_{\mathrm{t}}$ & total $\mathrm{Cu}(\%)$ \\
\hline$M_{\mathrm{t}}$ & total amount of chips $(\mathrm{g})$ \\
\hline$C_{\mathrm{m}}$ & $\mathrm{Cu}(\%)$ of matrix \\
\hline$C_{\mathrm{r}}$ & $\mathrm{Cu}(\%)$ of rock \\
\hline$M_{\mathrm{r}}$ & amount of cut rock (g) (calculated) \\
\hline SWR & specific wear rate $\left(\mathrm{mg} / \mathrm{m}^{2}\right)$ \\
\hline$W_{\mathrm{m}}$ & total wear of the saw-blade matrix (mg) \\
\hline$L$ & the cutting distance $(\mathrm{m})$ \\
\hline hm & $\begin{array}{l}\text { mean chip thickness produced by a single diamond } \\
\text { grit }\end{array}$ \\
\hline$V_{\mathrm{f}}$ & traverse speed \\
\hline$V_{\mathrm{c}}$ & peripheral speed \\
\hline$C$ & active diamond grits number per unit area \\
\hline$\lambda$ & $\begin{array}{l}\text { the ratio of segment to segment length to segment } \\
\text { length }\end{array}$ \\
\hline$r$ & $\begin{array}{l}\text { chip shape factor (ratio of mean chip width to mean } \\
\text { chip thickness) }\end{array}$ \\
\hline$d$ & depth of cut \\
\hline$D^{\prime}$ & diameter of saw blade \\
\hline
\end{tabular}

\section{References}

[1] Montani C 2016 XXVII World Marble and Stones Report. Carrara: Aldus

[2] Yurdakul M 2015 Effect of cutting parameters on consumed power in industrial granite cutting processes performed with the multi-disc block cutter. Int. J. Rock Mech. Min. Sci. 76: 104-111

[3] Aydin G, Karakurt I and Aydiner K 2013 Development of predictive models for the specific energy of circular diamond saw blades in the sawing of granitic rocks. Rock Mech. Rock Eng. 46: 767-783
[4] Aslantas K, Özbek O, Ucun I and Buyuksagis I S 2009 Investigation of the effect of axial cutting force on circular diamond saw blade used in marble cutting process. Mater. Manuf. Processes 24: 1423-1430

[5] Atıc1 U and Ersoy A 2009 Correlation of specific energy of cutting saws and drilling bits with rock brittleness and destruction energy. J. Mater. Process. Technol. 209: 2602-2612

[6] Ersoy A and Atıc1 U 2004 Performance characteristics of circular diamond saws in cutting different types of rocks. Diam. Relat. Mater. 13: 22-37

[7] Li Y, Huang H, Shen J Y, Xu X P and Gao Y S 2002 Costeffective machining of granite by reducing tribological interactions. J. Mater. Process. Technol. 129: 389-394

[8] Yilmaz N G 2016 Size analysis of the chips generated during abrasive machining of granite in relation to productivity and efficiency parameters. Particul. Sci. Technol. 34: 593-601

[9] Goktan R M and Yilmaz N G 2017 Diamond tool specific wear rate assessment in granite machining by means of Knoop micro-hardness and process parameters. Rock Mech. Rock Eng. 50: 2327-2343

[10] Aydin G, Karakurt I and Hamzacebi C 2015 Performance prediction of diamond saw blades using artificial neural network and regression analysis. Arab. J. Sci. Eng. 40: 2003-2012

[11] Tumac D 2015 Predicting the performance of large diameter circular saws based on Schmidt hammer and other properties for some Turkish carbonate rocks. Int. J. Rock Mech. Min. Sci. 75: 159-168

[12] Tumac D 2016 Artificial neural network application to predict the sawability performance of large diameter circular saws. Measurement 80: 12-20

[13] Aydin G, Karakurt I and Aydiner K 2013 Wear performance of saw blades in processing of granitic rocks and development of models for wear estimation. Rock Mech. Rock Eng. 46: $1559-1575$

[14] Yilmaz N G 2013 Process efficiency comparison of a sandwich-core saw blade and a conventional saw blade used in stone-machining. J. Clean Prod. 47: 26-31

[15] Ataei M, Mikaeil R, Hoseinie S H and Hosseini S M 2012 Fuzzy analytical hierarchy process approach for ranking the sawability of carbonate rock. Int. J. Rock Mech. Min. Sci. 50: 83-93

[16] Mikaeil R, Haghshenas S S, Haghshenas S S and Ataei M 2016 Performance prediction of circular saw machine using imperialist competitive algorithm and fuzzy clustering technique. Neural Comput. Appl. 29: 283-292

[17] Bayram F 2013 Prediction of sawing performance based on index properties of rocks. Arab. J. Geosci. 6: 4357-4362

[18] Alber M 2008 Stress dependency of the Cerchar abrasivity index (CAI) and its effects on wear of selected rock cutting tools. Tunnel. Undergr. Space Technol. 23: 351-359

[19] Tönshoff H K, Hilmann-Apmann H and Asche J 2002 Diamond tools in stone and civil engineering industry: cutting principles, wear and applications. Diam. Relat. Mater. 11: 736-741

[20] Rosa L G, Amaral P M, Anjinho C A and Fernandes J C 2004 Evaluation of diamond tool behaviour for cutting stone materials. Ind. Diam. Rev. 1: 46-50

[21] Bayram F, Yasitli N E, Kulaksiz S and Ozcelik Y 2012 Optimization of limestone sawing using circular saws with 
reference to unit wear and energy. Proc. Inst. Mech. Eng. C: J. Mech. Eng. Sci. 227: 1069-1079

[22] Büttner A 1974 Diamond tools and stone. Ind. Diam. Rev. 34: 89-93

[23] Luo S Y and Liao Y S 1995 Study of behaviour of diamond saw-blades in stone processing. J. Mater. Process. Technol. 51: $296-308$

[24] Ilio A D and Togna A 2003 A theoretical wear model for diamond tools in stone cutting. Int. J. Mach. Tool Manuf. 43: 1171-1177

[25] Ersoy A, Buyuksagic S and Atici U 2004 Wear characteristics of circular diamond saws in the cutting of different hard abrasive rocks. Wear. 258: 1422-1436

[26] Buyuksagis I S 2007 Effect of cutting mode on the sawability of granites using segmented circular diamond saw blade. $J$. Mater. Process. Technol. 183: 399-406

[27] Yilmaz N G 2011 Abrasivity assessment of granitic building stones in relation to diamond tool wear rate using mineralogy-based rock hardness indexes. Rock Mech. Rock Eng. 44: 725-733

[28] Yilmaz N G, Goktan R M and Kibici Y 2011 An investigation of the petrographic and physicomechanical properties of true granites influencing diamond tool wear performance, and development of a new wear index. Wear 271: 960-969

[29] Amaral P M, Fernandes J C and Rosa L G 2009 Wear mechanisms in materials with granitic textures-applicability of a lateral crack system model. Wear 266: 753-764
[30] Ucun I and Buyuksagis I S 2009 Using of laser measurement system in determination of diamond segment wear. In: Proceedings of the 5th International Advanced Technology Symposium, Karabuk, Turkey, pp. 1553-1556 (in Turkish)

[31] Roy R K 2001 Design of experiments using the Taguchi approach: 16 steps to product and process improvement. New York: Wiley-Inter science

[32] Ucun I, Gokce B, Eken M S, Aslantas K, Buyuksagis I S and Tasgetiren S 2015 Determination of optimum cutting parameters in sawing process using diamond cutting disc by Taguchi method. AKU J. Sci. Eng. 15: 6-16 (in Turkish)

[33] Montgomery D C 2001 Design and analysis of experiments. New York: Wiley

[34] Liao Y S and Luo S Y 1992 Wear characteristics of sintered diamond composite during circular sawing. Wear 157: 325-337

[35] Ertingshausen W 1985 Wear processes in sawing hard stone. Ind. Diam. Rev. 5: 254-258

[36] Karakus A 2007 Investigation of optimum stripe sawing conditions for some marble units and relations with rock properties. Ph.D. Thesis, Cumhuriyet University, Sivas, (in Turkish)

[37] Konstanty J 2002 Theoretical analysis of stone sawing with diamond. J. Mater. Process. Technol. 123: 146-154

[38] Tönshoff H K and Warnecke G 1982 Research on stone sawing. Daniel P (Ed.) Advances in ultrahard materials application technology. Hornbeam, London, England: De Beers Industrial Diamond Division, vol. 1, pp. 36-49 